\title{
The Wellbeing Effect Of Education: Uma Análise Da Relação Entre Gastos Em Educação e os Resultados Sociais No Brasil
}

\section{The Wellbeing Effect Of Education: An Analysis of the Relationship Between Education Expenditures and Social Results in Brazil}

\author{
Leonardo Flach ${ }^{1}$, Luísa Karam de Mattos ${ }^{1}$ \\ ${ }^{1}$ Universidade Federal de Santa Catarina, UFSC, Brasil. \\ Correspondência: Leonardo Flach. Rua Itapeva, Itacorubi, CEP 88.034-520, Florianópolis, SC, Brasil. Telefone: \\ +55 (48) 3334-4829. E-mail: leonardo.flach@gmail.com.
}

Recebido: 10 de dezembro de 2017 Aceito: 28 de setembro de 2018 Publicado: 28 de dezembro de 2018

DOI: http://dx.doi.org/ 10.21714/1679-18272018v16n1.p16-29

\begin{abstract}
Resumo
Esta pesquisa tem por objetivo analisar a relação entre os gastos realizados pelos estados brasileiros com Educação entre os anos de 2001 e 2010 e os resultados sociais apresentados pelas unidades da Federação de acordo com o censo do IBGE de 2010. Para isso, utilizou-se abordagem estatística com dados em séries temporais para analisar os efeitos dos gastos da educação nos resultados sociais, e foi elaborado um ranking da qualidade dos gastos públicos em educação. Os estados foram segregados de acordo com a relação entre gastos e resultados sociais. Os resultados evidenciam que o Piauí é destaque positivo pela boa colocação em resultados sociais com poucos gastos públicos com educação. Os estados do Acre e Rondônia se destacam negativamente por apresentarem baixos resultados sociais com altos gastos públicos com educação. Em termos gerais, esta pesquisa permitiu analisar, para cada um dos 27 estados brasileiros e ao longo dos anos, a relação existente entre os gastos públicos com educação e os resultados dos indicadores sociais, bem como permitiu gerar um ranking de eficiência entre os estados. Deste modo, os resultados desta pesquisa auxiliam no debate sobre o wellbeing efect of education, ou seja, o efeito de bem-estar social da educação.
\end{abstract}

Palavras-chave: Educação; Qualidade dos gastos; Despesas públicas.

\begin{abstract}
This research aims to analyze the relationship between the expenditures made by the Brazilian states with Education during the years from 2001 and 2010 and the social results presented by the units of the Federation according to the 2010 IBGE Census. The research method is quantitative, with application statistics with data in time series, in order to analyze the effects of education spending on social outcomes, and to elaborate a ranking of the quality of public expenditure on education. We segregated the Brazilian states according to the relationship between spending and social results. The results show that Piauí is a positive highlight due to the good placement in social results with few public spending on education. The states of Acre and Rondônia stand out negatively for presenting low social results with high public spending on education. In general terms, this research allowed to analyze, for each of the 27 Brazilian states and over the years, the relationship between public spending on education and the results of social indicators, as well as to elaborate a ranking of efficiency among states. Thus, the results of this research help in the debate about wellbeing efect of education, on the effects of education on social outcomes, for the wellbeing of the population.
\end{abstract}

Keywords: Education; Quality of expenditure; Public expenditure.

Esta obra está licenciada sob uma Licença Creative Commons Attribution 3.0.

\section{Introdução}

Os discursos sobre crescimento e desenvolvimento de um país, região, estado, ou qualquer outra unidade administrativa costumeiramente utilizam a necessidade de investimentos em educação como premissa necessária para impulsionar este crescimento. 
Bils e Klenow (2000) buscaram evidenciar, por meio de técnicas de correlação, se a escolaridade gera crescimento ou se o crescimento impulsiona a escolaridade. De acordo com o estudo, em que dois modelos foram construídos com base na literatura e em dados históricos da UNESCO, há evidências mais fortes de que o crescimento impulsiona a elevação no nível de escolaridade, do que a relação contrária, que se mostrou bastante fraca.

Não raro os discursos também utilizam, indiscriminadamente, valores absolutos de investimentos, tanto em educação como em outras funções de despesa, que podem ser impactantes pela sua expressividade numérica, mas que carecem de significado mais preciso. $\mathrm{O}$ valor de gastos em uma unidade administrativa, como um estado, por exemplo, precisa oferecer comparações mais objetivas para que a população, principal interessada na execução do orçamento público, possa tirar suas conclusões.

Além do fato de mencionar os valores de forma mais objetiva, fica sempre oculta a relação entre quantidade investida e retorno obtido: trata-se da qualidade do gasto público. Um ente pode variar os seus gastos entre um período e outro, e pode gastar mais ou menos do que o outro, em valores absolutos, mas as conclusões acerca da qualidade do gasto público ainda assim ficam bastante restritas se não forem comparadas, também, as variações qualitativas alcançadas pelas decisões que influenciam no quantitativo das despesas em cada função.

A atuação do setor público por meio dos serviços oferecidos para o bem-estar da população não acontece em um mercado competitivo, como na iniciativa privada. $\mathrm{O}$ fato de não haver sinalização de preços ao mercado não significa que não seja possível instituir outros mecanismos competitivos para avaliação dos serviços oferecidos pelo poder público. Alonso (1999) sugere que a competição "via preços" poderia ser substituída pela comparação "via indicadores de desempenho".

No Brasil, a responsabilidade pelos serviços de educação pública é compartilhada pelas três esferas de governo: federal, estadual e municipal. Os estados da Federação e o Distrito Federal, assim como os municípios, devem aplicar, no mínimo, $25 \%$ de sua arrecadação com impostos em educação, o que torna esta despesa pública uma das mais relevantes em termos financeiros. Seria incompleto mostrar os gastos dos estados com educação para evidenciar o seu comprometimento orçamentário sem considerar o seu desempenho social, ou seja, os resultados desfrutados pela população a partir de um conjunto de decisões de como aplicar recursos públicos, sejam elas de caráter técnico ou político.

A partir da falta de comparativos, nos demonstrativos públicos, entre gastos efetuados e resultados alcançados na esfera da administração pública, esta pesquisa apresenta como problemática: Qual é a relação entre os gastos com educação efetuados pelos estados brasileiros entre 2001 e 2010 e os índices sociais relacionados no censo do Instituto Brasileiro de Geografia e Estatística (IBGE) no ano de 2010?

Assim, esta pesquisa tem como objetivo verificar a relação entre os gastos em educação que os estados realizaram por meio de seu orçamento público e os índices de desempenho relacionados a esta área de despesa. Adicionalmente, a pesquisa fornece informações sobre gastos em educação per capita, que tornam os dados comparáveis, e uma síntese de indicadores relacionados à educação.

As grandes e diversas mudanças nas relações sociais que surgiram com o avanço das tecnologias, da economia e comunicação, estimularam os cidadãos a prezar para que a administração pública atenda as demandas da sociedade com maior agilidade e flexibilidade. Além disso, elas motivaram a qualidade do serviço público prestado, e exigiram que o estado busque novas alternativas e métodos de trabalho eficiente (KEINERT, 1994).

Cunha e Rocha (2012) explicam que o aumento da preocupação da sociedade com a eficiência e o desempenho do ensino superior é em parte justificada pela expansão dos sistemas de ensino superior. Outro ponto que os autores destacam refere-se aos desafios econômicos e às restrições do orçamento que pressionam ainda mais as universidades no que concerne ao gasto público.

A pesquisa justifica-se por abordar a relação entre investimentos em educação e um conjunto de indicadores relacionados a partir da seção 2 deste artigo. Espera-se que os estados com mais investimento, proporcionalmente, apresentem melhores índices de desempenho na educação. A partir dos resultados encontrados, poderão ser feitas considerações sobre a qualidade dos gastos públicos para a educação, de acordo com a satisfação da expectativa citada.

De acordo com Brunet, Bertê e Borges (2008), o processo de avaliação da qualidade do gasto público é importante para os governos, por oferecer mais transparência sobre a qualidade da educação ofertada, mostrando se os recursos públicos aplicados nas políticas educacionais estão propiciando serviços relacionados à escolaridade com qualidade.

Silva et al. (2011) destacam que a abordagem dos gastos públicos com educação apresenta diversas dificuldades, em razão de fatores como deficiências nas classificações orçamentárias, a falta de dados confiáveis, e também 
deficiências nos relatórios. Os autores afirmam que tratar da educação com seriedade não consiste mais em apenas um plano político de gestão pública, mas uma obrigação com a sociedade civil.

No Brasil, a situação das redes estaduais e municipais de ensino fundamental é crítica, quando verificados os elementos subjacentes ao aprendizado (SOBREIRA; CAMPOS, 2008). Sobreira e Campos (2008) explicam que determinadas facilidades, como acesso à biblioteca, laboratórios, computadores, por exemplo, são privilégios que existem para uma minoria dos alunos, até mesmo nas regiões mais prósperas do Brasil. Por essa razão, há disparidades inter-regionais na qualidade da educação, e diferenças entre o desempenho dos alunos da rede pública e dos alunos da rede privada no país.

Ao demonstrar aspectos gerenciais do orçamento público voltado à educação, este tipo de avaliação contribui para a transparência da gestão de recursos públicos, e permite que a população envolvida encontre dados que possam ser comparados, oferecendo uma contribuição para a redução da assimetria informacional.

\section{Revisão Teórica}

Com o objetivo de oferecer um aporte teórico ao trabalho realizado, o referencial teórico do presente estudo procura abordar conteúdo relacionado aos: a) aspectos legais dos gastos com educação; b) indicadores de resultado da educação no Brasil; c) transparência na gestão pública e avaliação dos gastos em educação.

\subsection{Aspectos legais dos gastos com educação}

Silva et al. (2011) entendem que é importante, para governo e população, examinar se esse percentual destinado à educação é administrado corretamente, com a busca de resultados para a administração. Com isso, é possível demonstrar o real interesse dos gestores na qualidade do serviço público e na área educacional.

Os investimentos em políticas educacionais, com a garantia de transparência e controle, devem ter como objetivo a melhoria dos níveis educacionais da população e, como consequência, o desenvolvimento do país (ANDRADE et al., 2011).

Sano e Tomoda (2010) destacam resultados de uma pesquisa sobre otimização de políticas públicas em educação, em que a estrutura de produção industrial afeta o sistema público de educação ideal. Isso ocorre porque o sistema de educação determina a distribuição e qualificação do capital humano. Assim, os trabalhadores escolhem o emprego de acordo com um padrão de vantagens comparativas, que sejam compactíveis com os seus níveis individuais de capital humano. Os níveis de habilidades requeridas dos trabalhadores dependem da estrutura de produção industrial. Esta, por sua vez, tem uma influência significativa na política de educação desejável. Desta forma, a extensão da produtividade e os tamanhos de mercado em todos os setores influenciam a política de educação ideal.

De acordo com o que estabelece a Constituição Federal de 1988, a educação é um direito social (artigo $6^{\circ}$ ) cujos meios de acesso devem ser proporcionados pela União, Estados, Distrito Federal e Municípios (artigo 23). Tratase de direito de todos e dever do Estado para o desenvolvimento da pessoa, preparo para o exercício da cidadania e qualificação para o trabalho (artigo 205), e será ministrada com base em alguns princípios, dentre os quais a garantia de padrão de qualidade (artigo 206, inciso VII).

A Carta Magna ainda estabelece a obrigatoriedade de percentuais mínimos para aplicação na educação: à União compete aplicar, no mínimo, dezoito por cento da receita de impostos na manutenção e desenvolvimento do ensino; para os Estados, Distrito Federal e Municípios, este percentual mínimo é de vinte e cinco por cento (artigo 212). Destaca-se que esta obrigatoriedade constitucional faz com que, ao efetuar a análise das despesas públicas por função dos balanços públicos de Estados e Municípios, a educação normalmente prevaleça sobre as demais funções de despesa como a principal consumidora (e beneficiária) de recursos.

A importância dada pela Constituição Federal ocorre com o estabelecimento da educação como direito de todos, cuja promoção é de competência comum da União, Estados, Distrito Federal e Municípios, e pelos incentivos à participação da sociedade. A destinação de valores mínimos, criando verdadeiros vínculos orçamentários das receitas para a aplicação de recursos no desenvolvimento e manutenção das atividades relacionadas à educação, também reforça o compromisso financeiro dos entes públicos com a educação no Brasil.

A operacionalização da aplicação dos recursos passa pelo orçamento público, que é um instrumento da moderna administração pública para autorização das despesas de um exercício (SILVA, 2004), por meio do qual o Poder Público expressa o seu programa de atuação, com o montante dos recursos a serem obtidos e dos dispêndios a serem efetuados (ROSA; TIMBÓ; PISCITELLI, 1997).

No contexto de orçamento público, a educação é uma despesa, definida por Silva (2004, p. 125) como um 
desembolso efetuado pelo Estado "no atendimento dos serviços e encargos assumidos no interesse geral da comunidade, nos termos da Constituição, das leis, ou em decorrência de contratos ou outros instrumentos".

As várias despesas realizadas pelo Estado para a satisfação da coletividade são consignadas no orçamento público por meio das dotações orçamentárias, que, conforme a classificação funcional estabelecida pela Portaria MOG n. ${ }^{\circ}$ 42/1999, são segregadas em funções e subfunções, de acordo com a área de atuação governamental em que são realizadas. Assim, a função Educação pode ser dividida em subconjuntos menores, que são as subfunções de despesa, como Ensino Fundamental, Ensino Médio, Ensino Superior, por exemplo, para facilitar a gestão dos recursos aplicados nesta área e evidenciar os gastos de forma pormenorizada.

\subsection{Indicadores de resultado da educação no Brasil}

Recentemente, a discussão a respeito da eficiência no setor público passou a ser cada vez mais foco de discussão e interesse para os gestores públicos. A alocação de recursos no setor público tem sido amplamente estudada e consiste em uma questão de grande importância (JHONES, 2006; COBACHO et al., 2010; MALCZEWSKI; JACKSON, 2000).

Cunha e Rocha (2012) explicam que a eficiência no setor público pode ser entendida como a máxima saída possível de um determinado conjunto de entradas. No contexto da educação, isto significa que a eficiência passou a ser associada ao relacionamento físico entre os recursos utilizados (capital, força de trabalho, equipamentos) e os resultados (boas notas, baixa evasão, bons indicadores sociais). Desta forma, as análises de eficiência na educação são utilizadas como forma de avaliar a eficiência com que os recursos estão sendo utilizados. Estes recursos e resultados fornecem um determinado nível de eficiência que representa uma medida de saída produzida, dado um determinado conjunto de entradas. Com isso, é possível examinar os resultados sociais gerados pela educação, levando em consideração os principais gastos empregados para o seu desenvolvimento.

De acordo com Rocha e Giuberti (2007), a literatura apresenta duas maneiras para avaliar a qualidade do gasto público e seu impacto sobre o crescimento. Uma delas, classificada como direta, procura medir o impacto do gasto público sobre o crescimento econômico por meio de análise estatística ou estudo de caso. A outra, classificada pelos autores como indireta, consiste em avaliar o resultado dos gastos que teriam um efeito positivo sobre o crescimento e tentar medir o desempenho do setor público relacionando as medidas de resultado com os insumos utilizados. A segunda forma de avaliação do gasto público (indireta) aproxima-se mais da proposta deste estudo, que analisa as medidas de resultado da educação e os insumos utilizados, reduzidos ao gasto per capita.

A falta de indicadores comparativos na área pública origina-se da própria ineficiência da administração pública, que não realiza o monitoramento dos resultados alcançados pelos recursos aplicados). E "a utilização sistemática de indicadores tem a vantagem de propiciar uma avaliação mais criteriosa e consistente, além de institucionalizar nas práticas organizacionais o compromisso com resultados e o valor pelo dinheiro" (ALONSO, 1999, p. 44).

No âmbito da educação, os indicadores são particularmente importantes por refletirem o capital humano de determinada área de atuação político-administrativa. Renzi (2008), ao estudar o gasto público em educação e o capital humano, faz um levantamento de estudos anteriores e aponta alguns indicadores de educação usados para medir o capital humano: anos de escolaridade, matrículas nas escolas, e matrículas nas universidades. Ainda, o autor entende que o gasto do governo em educação aumenta a capacidades de aprendizagem dos indivíduos, o que pode, consequentemente, torná-los mais criativos, elevar a produtividade no trabalho e elevar os ganhos para trabalhadores e empregadores.

Não obstante, a discussão sobre os indicadores sociais, os indicadores de despesa em educação também são necessários no trabalho de avaliação da qualidade do gasto público. A formulação e implementação de políticas na área da educação depende, inclusive, do conhecimento do gasto realizado e das prioridades estabelecidas, mensuradas em percentual do Produto Interno Bruto (PIB), percentual de gastos do orçamento em educação, gasto por habitante, ou gasto por aluno, mostrando o investimento unitário empreendido pelo governo (ALMEIDA, 2001).

Conforme detalhamento na seção 3 deste artigo, o Índice de Qualidade do Gasto Público é obtido por meio da relação entre diversos indicadores sociais de desempenho relacionados ao tipo de despesa analisada e o índice de despesa (em termos monetários). Os indicadores sociais de resultado retratam os resultados das políticas implementadas pelos governos estaduais em determinada função. $O$ índice da despesa representa a quantidade de recursos utilizados na função orçamentária Educação, e é utilizado de forma per capita, ou seja, considerando a despesa realizada por cada membro da população (BORGES, 2010).

Por meio de pesquisa na página eletrônica do IBGE (www.ibge.gov.br) é possível encontrar uma série de indicadores sociais relacionados ao grau de escolaridade e nível de educação no Brasil. O banco de dados oferece várias informações, que podem ser trabalhadas para o levantamento do alcance dos investimentos em Educação 
em cada estado do país. Pelo fato de o Censo do IBGE ser realizado a cada dez anos, e o último Censo do IBGE ter sido realizado no ano de 2010, os dados coletados para esta pesquisa referentes aos resultados sociais para cada um dos estados brasileiros referem-se aos resultados do Censo do IBGE do ano de 2010. Para permitir uma comparabilidade dos efeitos que os investimentos em Educação tiveram no resultado do Censo de 2010, foram também coletados e analisados os dados dos gastos em educação, para cada um dos 27 estados brasileiros, entre os anos de 2001 e 2010 (IBGE, 2012).

Para a realização desta pesquisa, foram utilizados alguns indicadores sociais, obtidos na página eletrônica do IBGE, e selecionados com base em indicadores sociais relacionados à educação, já aplicados antes por Borges (2010) em seu estudo sobre a qualidade do gasto público municipal, aplicado às microrregiões do estado do Rio Grande do Sul. Os indicadores sociais relacionados no presente estudo são:
a) Percentual de crianças de 0 a 5 anos na escola ou creche;
b) Percentual da população de 6 a 14 anos que frequenta a escola;
c) Percentual da população de 15 a 17 anos que frequenta a escola;
d) Percentual da população de 18 a 24 anos que frequenta a escola;
e) Média de anos de estudo das pessoas de 25 anos ou mais de idade;
f) Taxa bruta de frequência à escola;
g) Taxa de alfabetização.

Portanto, este conjunto de índices pode refletir a situação em que se encontra a educação nos estados brasileiros. A taxa de alfabetização é um dos mais conhecidos, mas, isoladamente, não reflete os resultados dos gastos em educação. Ao demonstrar os anos de estudo de pessoas com mais de 25 anos de idade e os percentuais de frequência à escola das diversas faixas de idade é possível obter uma percepção quantitativa com menor viés, que aborda os gastos com vários tipos de educação formal (ensino fundamental, médio e superior), bem como o capital intelectual acumulado médio (por meio dos anos de estudo, que inclui aqueles que já não frequentam mais a educação formal, mas que já frequentaram).

2.3 Transparência na gestão pública e avaliação dos gastos em educação

A transparência governamental consiste em uma condição principal. Afinal, são os mecanismos de controle e a fiscalização que, de fato, condicionam a transparência e visibilidade das ações do poder público. A responsabilização é um passo seguinte ao alcance da transparência, e, de acordo com os autores, ocorre apenas mediante a incorporação de normas, regras e mecanismos aptos para punir os agentes públicos (CENEVIVA; FARAH, 2012).

Passador e Calhado (2012) analisaram a infraestrutura escolar e o perfil socioeconômico dos alunos. Com informações atreladas aos resultados obtidos em provas de âmbito nacional pelos alunos, as autoras concluíram que há fatores intangíveis que influenciam o desempenho das escolas. A partir do levantamento de fatores favoráveis ao bom desempenho de escolas, as autoras observaram que nem sempre as escolas com mais fatores favoráveis são aquelas que possuem os melhores desempenhos.

Rocha (2011) chama a atenção para o fato de que o caráter de obrigação embutido no conceito de accountability caracteriza uma responsabilidade que é objetiva. $\mathrm{O}$ autor explica que a responsabilização objetiva, que está presente na accountability, passa a ser determinada por uma pessoa perante a outra. Este conceito difere-se da responsabilidade subjetiva, que vem de dentro da pessoa e se baseia na moralidade e na ética.

Ao oferecer informações comparativas entre os indicadores sociais e os índices de despesas, considera-se o objetivo de possibilitar aos interessados a compreensão de uma abordagem mais ampla sobre a qualidade dos gastos realizados pela administração pública, que pode conduzir a considerações sobre eficiência na aplicação de recursos públicos.

O acesso à informação compreensível para o usuário não é condição suficiente para a melhoria na alocação de recursos públicos, mas é fundamental para um governo que pretende empreender esforços na eficiência dos gastos públicos e melhorar seus indicadores sociais e de gestão. A transparência permite a avaliação das políticas e da gestão pública, e possibilita as correções em ações e projetos que não estiverem dentro das expectativas de sucesso (BORGES, 2010).

Castro (1998, p. 136) apresenta entendimento semelhante, ao afirmar que a avaliação dos gastos públicos aplicados na educação é de grande importância para a formulação e implementação das políticas educacionais. Isso porque 
os recursos públicos, ao propiciarem as principais condições materiais para viabilizar as políticas, "podem representar um limite e obstáculo intransponível ao atendimento das demandas educacionais, em quantidade e qualidade".

A importância de estudar os resultados de eficiência nos gastos públicos deve-se ao fato de que, nem sempre, a maior aplicação de recursos repercute em qualidade. Os resultados da pesquisa desenvolvida por Faria, Jannuzzi e Silva (2008) acerca da eficiência dos gastos municipais com educação e saúde em unidades municipais do estado do Rio de Janeiro evidenciou que alguns municípios atuaram com eficiência dispondo de poucos recursos; a situação inversa também foi verificada, ou seja, o mau gasto de recursos públicos também foi observado.

Os resultados de sucesso na educação, assim como em qualquer área de aplicação de recursos públicos, exigem o acompanhamento dos resultados pelos gestores. Assim, a avaliação dos gastos públicos por meio de comparações busca suprir a inexistência de preços para os serviços executados pela administração pública.

As pressões por aumento da transparência e do nível de informações sobre a gestão pública e a normatização de regras que institucionalizam a responsabilidade fiscal abrem espaço para o aperfeiçoamento dos relatórios oferecidos pela contabilidade pública, que tradicionalmente não ofereciam informações compatíveis com as necessidades e entendimento de gestão da população e dos próprios gestores de recursos públicos.

As mudanças recentes culminam na necessidade de adoção, pelo setor público, de sistemas contábeis semelhantes aos da iniciativa privada, adequadas para possibilitar o conhecimento do custo dos bens e serviços produzidos por organizações governamentais. $\mathrm{O}$ formato dos relatórios atuais não permite que os custos sejam comparados aos resultados, dificultando a avaliação da eficiência das ações governamentais e a análise de alternativas que poderiam obter idênticos resultados com custos menores (REZENDE; CUNHA; BEVILACQUA, 2010).

Segundo Slomski et al. (2010), sob qualquer prisma que se observe a relação entre o Estado e seus cidadãos, é importante não ignorar a necessidade de prestação de contas ampla e transparente por parte dos agentes públicos, com a avaliação sobre o desempenho dos gestores públicos.

Por fim, considera-se que a abordagem adotada neste trabalho permite aplicação para qualquer outra função de despesa. A partir de indicadores sociais relacionados à saúde, segurança ou infraestrutura, entre outros, pode ser realizado o mesmo trabalho de decomposição de dados, pela sua relação com os índices de despesa da respectiva função. Deste modo, são oferecidas aos usuários outras possibilidades de acesso e entendimento sobre a gestão pública e os resultados efetivamente alcançados.

\section{Método}

Sobre a classificação metodológica, esta é uma pesquisa descritiva, com abordagem de dados quantitativa e utilização de procedimentos estatísticos. Sua operacionalização ocorreu por meio de levantamento de dados, utilizando também pesquisa bibliográfica e documental.

A pesquisa tem como objetivo verificar o grau de correlação entre os gastos com educação efetuados pelos estados do Brasil de 2001 a 2010 e os índices sociais de educação relacionados no censo do Instituto Brasileiro de Geografia e Estatística (IBGE) do ano de 2010. Considera-se a pesquisa como descritiva, pois tem por fim a descrição das características de determinada população, buscando identificar possíveis relações entre as variáveis, utilizando de forma recorrente a comparação e o contraste entre objetos de estudo (SALOMON, 1996; GIL, 2010).

Segundo Raupp e Beuren (2004, p.89), a pesquisa documental "baseia-se em materiais que ainda não receberam um tratamento analítico ou que podem ser reelaborados de acordo com os objetivos da pesquisa". Assim, esta pesquisa é classificada como documental em razão da realização de coleta de dados junto ao Instituto Brasileiro de Geografia e Estatística (IBGE).

A abordagem quantitativa, conforme Gil (2010), é frequentemente utilizada nos estudos descritivos que procuram descobrir relações entre variáveis. Neste trabalho utiliza-se de procedimento estatístico para relacionar duas variáveis, que, segundo o mesmo autor, é considerado adequado para obter o melhor entendimento sobre como fatores e elementos influenciam sobre determinado fenômeno.

Esta pesquisa estabelece um ranking de melhor utilização de recursos públicos, e utiliza o valor dos gastos em educação constantes no orçamento público dos estados brasileiros, inclusive o Distrito Federal, e um índice que compreenda os indicadores sociais de resultados relacionados à educação. Estes indicadores são discutidos na seção 2.2 deste trabalho, e versam sobre: percentual de crianças de 0 a 5 anos na escola ou creche; percentual da população de 6 a 14 anos que frequenta a escola; percentual da população de 15 a 17 anos que frequenta a escola; percentual da população de 18 a 24 anos que frequenta a escola; média de anos de estudo das pessoas de 25 anos ou mais de idade; taxa bruta de frequência à escola; taxa de alfabetização.

Cabe ressaltar que, conforme Borges (2010), o ranking não é obtido a partir da divisão de um índice pelo outro, 
mas sim de uma relação estabelecida através do posicionamento de cada elemento (estado) em relação aos demais. Assim, é possível verificar quais estados têm os melhores resultados em indicadores sociais, quais estão aplicando mais recursos, e, pela relação entre essas duas verificações, obter um terceiro resultado relacionado à qualidade do gasto público de um estado comparado aos demais.

O espaço de tempo delimitado compreende os anos de 2001 a 2010. Os valores dos orçamentos realizados de cada estado durante este período foram obtidos na página eletrônica da Secretaria do Tesouro Nacional (STN), vinculada ao Ministério da Fazenda. Os dados sobre o orçamento da função de despesa Educação são trabalhados em índices per capita, em que os gastos com educação são divididos pela população total dos estados.

Os dados sobre a população de cada estado são obtidos na página eletrônica do IBGE, que realiza o censo a cada dez anos: os últimos dois censos foram realizados em 2010 e 2000, e, conforme já mencionado, o período estudado nesta pesquisa compreende os anos de 2001 a 2010. Para estabelecer o quantitativo populacional dos anos não cobertos pelo censo do IBGE foram estimados os anos de 2001 a 2009 por meio de progressão aritmética entre a diferença dos dois levantamentos (2000 e 2010), conforme a seguinte fórmula:

$$
\mathrm{P}_{200 \mathrm{x}}=\mathrm{P}_{2000}+\left(\left(\mathrm{P}_{2010}-\mathrm{P}_{2000}\right) / 10 *(200 \mathrm{X}-2000)\right)
$$

Assim, para estabelecer o valor da população de determinado estado no ano de 2007, por exemplo, a diferença entre o valor encontrado nos dados de recenseamento do IBGE no ano de 2010 e o valor encontrado no ano de 2000 é dividida por dez (10) e multiplicado por sete (7), e depois acrescentada ao valor do ano de 2000. Por fim, é feita a média dos gastos em educação per capita e é utilizado este índice para comparação com os indicadores sociais de resultados.

Em relação aos indicadores sociais de resultados, já citados nesta seção, o procedimento estatístico adotado envolve uma combinação dos escores padronizados destes indicadores, que podem ou não ser ponderados de acordo com a avaliação do pesquisador. Para evitar a formação de juízo de valor, esta pesquisa atribuiu pesos iguais aos sete indicadores.

Assim, o índice de resultados da educação é obtido pela seguinte fórmula:

Resultado em Educação $=[(\mathrm{EB} 1-\mathrm{M} 1) / \mathrm{DP} 1]+\ldots+[(\mathrm{EB} 7-\mathrm{M} 7) / \mathrm{DP} 7]$

$\mathrm{N}$

Onde:

$\mathrm{EB}=$ Escore bruto do indicador social analisado para cada estado;

$\mathrm{M}=$ Média dos escores brutos de todos os estados para o indicador social analisado;

DP = Desvio padrão dos escores brutos de todos os estados para o indicador social analisado;

$\mathrm{N}=$ Número total de indicadores analisados (neste caso, 7).

A partir da obtenção dos dois índices (de resultados e de gastos) é elaborada uma tabela com o posicionamento de todos os estados, atribuindo-se uma pontuação a cada um pela sua posição em resultados e pela sua posição em gastos, conforme demonstrado na Quadro 1:

\begin{tabular}{|c|c|c|}
\hline \multirow{2}{*}{ Posição } & \multicolumn{2}{|c|}{ Pontuação } \\
\cline { 2 - 3 } & $\begin{array}{c}\text { Resultado em Educação } \\
\text { (quanto maior, melhor) }\end{array}$ & $\begin{array}{c}\text { Gasto per capita } \\
\text { (quanto menor, melhor) }\end{array}$ \\
\hline 1 & 27 & 1 \\
2 & 26 & 2 \\
3 & 25 & 3 \\
$\ldots$ & $\ldots$ & $\ldots$ \\
27 & 1 & 27 \\
\hline
\end{tabular}

Quadro 1: Pontuação para os resultados em educação e gastos per capita.

Fonte: Adaptado de Borges (2010).

Ao verificar a posição de cada estado, conforme a Figura 1, são extraídos os pontos obtidos e calculados os valores do Índice de Qualidade do Gasto Público para cada estado:

Qualidade do Gasto Público = Indicador de Resultado em Educação

Indicador de Despesas 
Em seguida, é elaborada uma relação que considera os resultados em qualidade do gasto público com educação, e, por meio de tabelas e figuras, são apresentadas as classificações obtidas pelos estados, que permitem ao leitor um detalhamento sobre os gastos públicos neste setor.

Assim, por meio da comparação entre as despesas selecionadas na classificação funcional dos orçamentos estaduais e os indicadores socioeconômicos que refletem os resultados das políticas públicas junto à população, é possível estabelecer uma hierarquia entre os estados brasileiros para a função educação (BORGES, 2010).

Destaca-se que o trabalho utilizou o tempo de 10 anos (2001 a 2010) por considerar que os resultados em educação de acordo com o censo realizado em 2010 não são reflexos de políticas públicas e investimentos nesta área de apenas um ano, ou qualquer outro período curto de tempo. Também é verificado, como limitação, o fato de não ser possível estabelecer um período de tempo adequado como causa dos resultados no curto ou no longo prazo, e tampouco é possível afirmar com certeza que estes resultados sejam reflexos dos investimentos realizados, ou se são de uma combinação de outros fatores somados.

O que se busca, com esta pesquisa, é a verificação da qualidade do gasto público a partir da premissa de que a educação é uma das responsabilidades e aplicações de recursos relevantes nas esferas de governo, cujos resultados devem aparecer no curto ou no longo prazo.

\section{Apresentação e Análise dos Dados}

Nesta seção são analisados os resultados encontrados por esta pesquisa. Primeiramente, são apresentadas considerações sobre duas variáveis que influenciaram o resultado final: os indicadores sociais em educação e os gastos per capita. Em seguida, é apresentado o ranking com o posicionamento dos estados de acordo com a metodologia adotada.

\subsection{Indicadores Sociais em Educação}

Para realizar o apontamento sobre os resultados oferecidos para a sociedade por meio dos recursos aplicados na educação, foram selecionados os indicadores sociais já descritos na seção 2.2 deste estudo.

A partir de pesquisa realizada na página eletrônica do IBGE foi elaborada a Tabela 1, em que são destacados os estados do Brasil com indicadores sociais superiores à média somada com o desvio-padrão da população, e os estados com indicadores sociais inferiores à média subtraída do desvio-padrão, e em seguida são feitas algumas inferências.

Tabela 1: Desempenho dos melhores e piores estados conforme indicadores sociais de 2010.

\begin{tabular}{|c|c|c|c|c|}
\hline Indicador Social & Média & $\begin{array}{l}\text { Desvio- } \\
\text { Padrão }\end{array}$ & Destaques Positivos & Destaques Negativos \\
\hline $\begin{array}{l}\% \text { que frequenta a escola } \\
\qquad(0-5 \text { anos })\end{array}$ & 40,03 & 6,80 & $\begin{array}{c}1^{\circ} \mathrm{SP}(50,75), 2^{\circ} \mathrm{SC}(50,20) \\
3^{\circ} \mathrm{CE}(49,68), 4^{\circ} \mathrm{RN}(48,99) \\
5^{\circ} \mathrm{RJ}(48,14)\end{array}$ & $\begin{array}{c}1^{\circ} \mathrm{RO}(26,59), 2^{\circ} \mathrm{AP}(29,17), \\
3^{\circ} \mathrm{AC}(29,70), 4^{\circ} \mathrm{AM}(30,75), \\
5^{\circ} \mathrm{GO}(32,72)\end{array}$ \\
\hline $\begin{array}{c}\% \text { que frequenta a escola } \\
(6-14 \text { anos })\end{array}$ & 96,18 & 1,80 & $\begin{array}{c}\text { População uniforme: nenhum } \\
\text { destaque superior }\end{array}$ & $\begin{array}{c}1^{\circ} \mathrm{AM}(91,20), 2^{\circ} \mathrm{RR}(91,69), \\
3^{\circ} \mathrm{AC}(91,83)\end{array}$ \\
\hline $\begin{array}{c}\% \text { que frequenta a escola } \\
(15-17 \text { anos })\end{array}$ & 82,5 & 2,32 & $\begin{array}{c}1^{\circ} \mathrm{CE}(88,43), 2^{\circ} \mathrm{RJ}(86,88), \\
3^{\circ} \mathrm{PI}(85,45), 4^{\circ} \mathrm{SP}(85,34), 5^{\circ} \\
\operatorname{SE}(85,21)\end{array}$ & $\begin{array}{c}1^{\circ} \mathrm{AC}(77,76), 2^{\circ} \mathrm{MS}(79,46), \\
3^{\circ} \mathrm{SC}(80,18)\end{array}$ \\
\hline $\begin{array}{l}\% \text { que frequenta a escola } \\
(18-24 \text { anos })\end{array}$ & 31,53 & 2,87 & $\begin{array}{l}1^{\circ} \mathrm{DF}(39,01), 2^{\circ} \mathrm{PI}(36,41) \\
3^{\mathrm{o}} \mathrm{AM}(36,02), 4^{\mathrm{o}} \mathrm{SE}(35,65)\end{array}$ & $\begin{array}{c}1^{\circ} \mathrm{CE}(26,60), 2^{\circ} \mathrm{ES}(26,82) \\
3^{\circ} \mathrm{RO}(27,97)\end{array}$ \\
\hline $\begin{array}{c}\text { Taxa Bruta Frequência a } \\
\text { Escola }\end{array}$ & & 3,63 & $\begin{array}{l}1^{\mathrm{o}} \mathrm{RR}(41,20), 2^{\circ} \mathrm{AP}(37,70) \\
3^{\mathrm{o}} \mathrm{AM}(36,60), 4^{\mathrm{o}} \mathrm{AC}(36,10)\end{array}$ & $\begin{array}{c}1^{\circ} \mathrm{RS}(26,20), 2^{\circ} \mathrm{RJ}(26,80), \\
3^{\circ} \mathrm{SP}(27,30), 4^{\circ} \mathrm{SC}(28,10), \\
5^{\circ} \mathrm{ES}(28,20), 6^{\circ} \mathrm{MG}(28,30), \\
7^{\circ} \mathrm{PR}(28,40)\end{array}$ \\
\hline $\begin{array}{l}\text { Média de anos de estudo } \\
\text { de maiores de } 25 \text { anos }\end{array}$ & oJ & 1,02 & $\begin{array}{c}1^{\mathrm{o}} \mathrm{DF}(9,50), 2^{\circ} \mathrm{RJ}(8,20), 2^{\circ} \\
\operatorname{SP}(8,20), 3^{\circ} \mathrm{AP}(8,00)\end{array}$ & $\begin{array}{c}1^{\circ} \operatorname{AL}(5,00), 2^{\circ} \operatorname{PI}(5,20), 3^{\circ} \\
\operatorname{MA}(5,60), 3^{\circ}\left(\operatorname{PB}(5,60), 4^{\circ}\right. \\
\operatorname{CE}(5,80)\end{array}$ \\
\hline Taxa de alfabetização & 88,78 & 5,89 & $\begin{array}{c}1^{\circ} \mathrm{DF}(96,75), 2^{\circ} \mathrm{SC}(96,14) \\
3^{\circ} \mathrm{RJ}(95,91), 3^{\circ} \mathrm{SP}(95,91) \\
4^{\circ} \operatorname{RS}(95,76)\end{array}$ & $\begin{array}{c}1^{\circ} \mathrm{AL}(77,48), 2^{\circ} \mathrm{PI}(78,86), \\
3^{\circ} \mathrm{PB}(79,80), 4^{\circ} \mathrm{MA}(80,69), \\
5^{\circ} \mathrm{RN}(82,62), 6^{\circ} \mathrm{CE}(82,81),\end{array}$ \\
\hline
\end{tabular}

Fonte: Dados da pesquisa.

A região Norte apresenta aspectos positivos relacionados ao indicador de frequência bruta da população em estabelecimentos de ensino, uma vez que esta região apresentou quatro estados em destaque neste indicador (AC, 
AP, AM, RR). Por outro lado, apresenta quatro estados entre os menores índices de frequência a escola ou creche para menores de 5 anos (RO, AP, AC, AM). Este fato pode ser explicado pela característica menos urbana desta região, o que contribui para que as crianças menores não frequentem estabelecimentos de ensino tão cedo pelo fato de poderem ficar com pais ou familiares em tempo integral durante os primeiros anos da infância. Nesta região também estão os estados que apresentaram os pontos negativos mais discrepantes na frequência da população de 6-14 anos (AC, AM, RR), sendo que este índice mostrou uma frequência muito parecida em todos os demais estados. Como destaque individual positivo desta região, o estado do Amapá apresentou bons índices de frequência bruta $(37,70 \%)$ e a terceira melhor média $(8,00)$ de anos de estudo para maiores de 25 anos do país. O estado do Acre, apesar de altos índices de frequência bruta (36,10\%), apresentou baixos índices de frequência para as faixas etárias de 0 a 17 anos. $\mathrm{O}$ índice positivo pode ser reflexo de uma busca por escolaridade e qualificação após o período normal esperado para as respectivas faixas etárias.

Em relação à região Nordeste, apresenta dois estados com altos índices de frequência à escola ou creche para menores de 5 anos (CE e RN), e também dois outros estados com altos índices de frequência para a faixa etária de 15 a 17 anos e de 18 a 24 anos (PI e SE). O estado do Piaú, apesar de aparecer com destaque positivo, está relacionado com outros quatro estados (AL, CE, MA, PB) entre as menores médias de anos de estudo para pessoas com mais de 25 anos: nenhum deles com média superior a 6,00. Os mesmos estados, acompanhados ainda do Rio Grande do Norte, apresentam as menores taxas de alfabetização: mais de $17 \%$ da população de cada um destes estados é considerada analfabeta.

Da região Centro-Oeste o Distrito Federal é o grande destaque: apresenta alta frequência escolar para a população entre 15 e 17 anos (88,43\%) e entre 18 e 24 anos (39,01\%). Além disso, apresenta a mais alta média de anos de estudo $(9,5)$ para a população com mais de 25 anos e a mais baixa taxa de analfabetos do país $(3,25 \%)$. O fato de ser a sede da capital do país pode ser um dos fatores que contribuem essencialmente para o alcance desses índices.

No Sudeste do país todos os estados estão relacionados entre os menores índices de frequência bruta da população a estabelecimentos de ensino. Por comportarem as duas principais metrópoles do país (São Paulo e Rio de Janeiro), esta região também atrai grande quantidade de pessoas, que muitas vezes já estão formadas e não estudam mais. Apesar do destaque negativo, tanto São Paulo quanto Rio de Janeiro estão entre os estados com melhores resultados para quatro índices: taxa de frequência escolar de menores de 5 anos, taxa de frequência escolar entre 15 e 17 anos, média de anos de estudo (só perdendo para o Distrito Federal) e maiores taxas de alfabetização (perdendo também apenas para o Distrito Federal e para Santa Catarina).

A região Sul forma, junto com a região Sudeste, o conjunto dos menores índices de frequência bruta a escola. Apresenta, também, dois estados com as maiores taxas de alfabetização do Brasil: Santa Catarina (96,14\%) e Rio Grande do Sul $(95,76 \%)$.

A pretensão não é exaurir a discussão, mas fazer um breve relato geral dos principais destaques de cada região entre indicadores positivos e negativos, considerando a média e o desvio-padrão de todos os valores para cada item analisado, para, em seguida, possibilitar a formulação de considerações a respeito dos indicadores de qualidade do gasto público.

\subsection{Gastos per capita em educação}

Esta seção apresenta os estados brasileiros de acordo com o gasto médio per capita durante os anos de 2001 a 2010. Importa dizer que os valores foram reajustados monetariamente, pois a aplicação de correção implica em posicionamento diferente dos estados, o que interfere no resultado do ranking, que considera essencialmente o posicionamento dos elementos para cada variável. Cabe salientar, ainda, que para este estudo não foi constatada diferença entre o posicionamento com ou sem correção monetária de valores, não cabendo, portanto, o aprofundamento da discussão para esta etapa metodológica.

A Tabela 2 apresenta os estados de acordo com o seu enquadramento nas faixas de gasto por educação anual per capita, considerando a média dos anos de 2001 a 2010, e a atualização monetária dos valores até o último ano:

Tabela 2: Gastos médios anuais per capita em educação dos estados brasileiros de 2001 a 2010.

\begin{tabular}{c|c}
\hline Faixa de Valor & Estados \\
\hline Mais de R\$ 500,00. & $1^{\circ} \mathrm{RR}(815,12), 2^{\circ} \mathrm{AP}(742,10), 3^{\circ} \mathrm{AC}(681,32), 4^{\circ} \mathrm{DF}(675,72)$ \\
\hline Entre R\$ 499,99 e 400,00 & $5^{\circ} \mathrm{SP}(497,74), 6^{\circ} \mathrm{TO}(416,21)$ \\
\hline Entre R\$ 399,99 e 300,00 & $7^{\circ} \mathrm{RJ}(366,93), 8^{\circ} \mathrm{RO}(346,61), 9^{\circ} \mathrm{PR}(339,57), 10^{\circ} \mathrm{AM}(320,99), 11^{\circ} \mathrm{MS}$ \\
\hline
\end{tabular}




\begin{tabular}{|c|c|}
\hline & $\begin{array}{c}(308,26) \\
12^{\circ} \mathrm{MT}(302,57)\end{array}$ \\
\hline Entre $\mathrm{R} \$ 299,99$ e 200,00 & $\begin{array}{c}13^{\circ} \mathrm{SC}(297,54), 14^{\circ} \mathrm{RS}(292,63), 15^{\circ} \mathrm{SE}(287,80), 16^{\circ} \mathrm{GO}(280,78), 17^{\circ} \mathrm{RN} \\
(271,74), \\
18^{\circ} \mathrm{CE}(267,36), 19^{\circ} \mathrm{ES}(260,87), 20^{\circ} \mathrm{MG}(252,83), 21^{\circ} \mathrm{PB}(215,51), 22^{\circ} \mathrm{PI} \\
(200,42)\end{array}$ \\
\hline Menos de R\$ 200,00 & $23^{\circ} \mathrm{AL}(189,81), 24^{\circ} \mathrm{BA}(186,88), 25^{\circ} \mathrm{MA}(172,35), 26^{\circ} \mathrm{PA}(160,14), 27^{\circ} \mathrm{PE}$ \\
\hline
\end{tabular}

Fonte: Dados da pesquisa.

A Tabela 2 simplifica a relação quantitativa entre os gastos orçamentários da função Educação (em despesas correntes e despesas de capital) e a população residente em cada estado. Assim, alcança-se uma medida comparativa, em que podem ser observadas grandes discrepâncias entre alguns estados.

Entre os cinco estados com menor gasto per capita, quatro pertencem à região Nordeste: Alagoas, Bahia, Maranhão e Pernambuco. Entre os menores gastos figura, ainda, o estado do Pará, pertencente à região Norte do país.

De outro lado, existe uma lista de estados que gastam mais do que o dobro do valor per capita apresentado por outros em educação. O estado de Roraima, por exemplo, gasta em educação mais do que o quádruplo do que gastam os seis estados com menor valor (cinco deles já citados no parágrafo anterior, e ainda o estado do Piauí). Outros três estados da região Norte também apresentam altos gastos per capita (Amapá, Acre e Tocantins), além do Distrito Federal e de São Paulo.

Por fim, percebe-se que os estados da região Norte que figuram entre os maiores gastos per capita estão entre os cinco com as menores despesas totais em educação. $\mathrm{O}$ fato ocorre em razão de os estados também terem as menores populações. Os valores direcionados à educação podem ser explicados pelos mínimos constitucionais (seção 2.1 desta pesquisa), que devem ser obrigatoriamente empregados nesta área. Assim, estes estados figuram na parte inferior do ranking, conforme demonstrado na seção 4.3, pois os indicadores sociais não correspondem ao alto valor gasto para a área.

\subsection{Qualidade do gasto público}

O cálculo do Índice de Qualidade do Gasto Público (IQGP) é obtido por meio da divisão da pontuação do estado de acordo com a posição do seu índice dos resultados sociais em educação pela pontuação de acordo com a posição do seu índice de gastos per capita. Não é adequado relacionar os resultados sociais a apenas um período, como se fossem consequência dos investimentos apenas daquele ano. Tampouco é possível afirmar o período exato em que os gastos podem trazer retorno mensurável em indicadores sociais. Entre as limitações desta metodologia incluise o fato de que os indicadores sociais não são resultado exclusivo dos gastos feitos pelo setor público.

As considerações também são limitadas pelo posicionamento relativo de cada estado. Assim, um estado com baixos indicadores sociais pode tornar-se bem posicionado em relação à qualidade do gasto público se sua posição em gastos for ainda inferior aos resultados alcançados. Da mesma forma, um estado com altos gastos e excelentes indicadores sociais pode ter sua posição em qualidade afetada pela relação resultados/gastos. Essas restrições ficarão evidenciadas após análise da Tabela 3.

Tabela 3: IQGP em educação dos estados brasileiros em 2010.

\begin{tabular}{|c|c|c|c|c|c|c|c|c|}
\hline \multirow{2}{*}{ Estado } & \multicolumn{3}{|c|}{ Resultado em Educação } & \multicolumn{3}{|c|}{ Gastos per capita } & \multirow{2}{*}{ IQGP } & \multirow{2}{*}{$\begin{array}{c}\text { Posição } \\
\text { Final }\end{array}$} \\
\hline & Índice & Posição & Pontuação & Índice & Posição & Pontuação & & \\
\hline Acre & $-5,79$ & $27^{\circ}$ & 1 & 681,32 & $3^{\circ}$ & 25 & 0,04 & $27^{\circ}$ \\
\hline Alagoas & $-4,20$ & $26^{\circ}$ & 2 & 189,81 & $23^{\circ}$ & 5 & 0,40 & $24^{\circ}$ \\
\hline Amapá & 2,32 & $4^{\circ}$ & 24 & 742,10 & $2^{\circ}$ & 26 & 0,92 & $18^{\circ}$ \\
\hline Amazonas & $-1,44$ & $19^{\circ}$ & 9 & 320,99 & $10^{\circ}$ & 18 & 0,50 & $22^{\circ}$ \\
\hline Bahia & $-0,44$ & $14^{\circ}$ & 14 & 186,88 & $24^{\circ}$ & 4 & 3,50 & $4^{\circ}$ \\
\hline Ceará & $-2,23$ & $24^{\circ}$ & 4 & 267,36 & $18^{\circ}$ & 10 & 0,40 & $25^{\circ}$ \\
\hline Distrito Federal & 10,13 & $1^{\circ}$ & 27 & 675,72 & $4^{\circ}$ & 24 & 1,13 & $12^{\circ}$ \\
\hline Espírito Santo & $-1,27$ & $17^{\circ}$ & 10 & 260,87 & $19^{\circ}$ & 9 & 1,11 & $13^{\circ}$ \\
\hline Goiás & $-0,75$ & $15^{\circ}$ & 13 & 280,78 & $16^{\circ}$ & 12 & 1,08 & $15^{\circ}$ \\
\hline Maranhão & $-1,34$ & $18^{\circ}$ & 11 & 172,35 & $25^{\circ}$ & 3 & 3,67 & $2^{\circ}$ \\
\hline Mato Grosso & $-0,95$ & $16^{\circ}$ & 12 & 302,57 & $12^{\circ}$ & 16 & 0,75 & $19^{\circ}$ \\
\hline Mato Grosso do Sul & $-1,70$ & $21^{\circ}$ & 8 & 308,26 & $11^{\circ}$ & 17 & 0,47 & $23^{\circ}$ \\
\hline Minas Gerais & $-0,04$ & $12^{\circ}$ & 16 & 252,83 & $20^{\circ}$ & 8 & 2,00 & $6^{\circ}$ \\
\hline
\end{tabular}




\begin{tabular}{lrrrrrrrr}
\hline Pará & $-1,93$ & $22^{\circ}$ & 6 & 160,14 & $26^{\circ}$ & 2 & 3,00 & $5^{\circ}$ \\
\hline Paraíba & $-1,99$ & $23^{\circ}$ & 5 & 215,51 & $21^{\circ}$ & 7 & 0,71 & $20^{\circ}$ \\
\hline Paraná & 0,50 & $10^{\circ}$ & 19 & 339,57 & $9^{\circ}$ & 19 & 1,00 & $16^{\circ}$ \\
\hline Pernambuco & $-1,62$ & $20^{\circ}$ & 7 & 146,50 & $27^{\circ}$ & 1 & 7,00 & $1^{\circ}$ \\
\hline Piauí & 1,95 & $6^{\circ}$ & 22 & 200,42 & $22^{\circ}$ & 6 & 3,67 & $3^{\circ}$ \\
\hline Rio de Janeiro & 5,39 & $2^{\circ}$ & 26 & 366,93 & $7^{\circ}$ & 21 & 1,24 & $10^{\circ}$ \\
\hline $\begin{array}{l}\text { Rio Grande } \\
\text { Norte }\end{array}$ & $-0,16$ & $13^{\circ}$ & 15 & 271,74 & $17^{\circ}$ & 11 & 1,36 & $8^{\circ}$ \\
\hline Rio Grande do Sul & 0,08 & $11^{\circ}$ & 17 & 292,63 & $14^{\circ}$ & 14 & 1,21 & $11^{\circ}$ \\
\hline Rondônia & $-4,07$ & $25^{\circ}$ & 3 & 346,61 & $8^{\circ}$ & 20 & 0,15 & $26^{\circ}$ \\
\hline Roraima & 0,54 & $9^{\circ}$ & 18 & 815,12 & $1^{\circ}$ & 27 & 0,67 & $21^{\circ}$ \\
\hline Santa Catarina & 1,65 & $7^{\circ}$ & 20 & 297,54 & $13^{\circ}$ & 15 & 1,33 & $9^{\circ}$ \\
\hline São Paulo & 3,67 & $3^{\circ}$ & 25 & 497,94 & $5^{\circ}$ & 23 & 1,09 & $14^{\circ}$ \\
\hline Sergipe & 2,27 & $5^{\circ}$ & 23 & 287,80 & $15^{\circ}$ & 13 & 1,77 & $7^{\circ}$ \\
\hline Tocantins & 1,42 & $8^{\circ}$ & 21 & 416,21 & $6^{\circ}$ & 22 & 0,95 & $17^{\circ}$ \\
\hline
\end{tabular}

Fonte: Dados da pesquisa.

O estudo aponta que os estados com menores gastos per capita apresentam os melhores IQGP. Apesar de não apresentarem resultados expressivos nos indicadores sociais, o posicionamento alcançado pelos estados, com tão poucos recursos, faz com que alcancem posições de destaque em relação à qualidade do gasto.

Assim, os estados de Pernambuco (menor gasto per capita e $20^{\circ}$ colocado em índices de educação), Maranhão ( $3^{\circ}$ menor gasto per capita e $18^{\circ}$ colocado em índices de educação), Bahia ( $4^{\circ}$ menor gasto per capita e $14^{\circ}$ colocado em índices de educação) e Pará ( $2^{\circ}$ menor gasto per capita e $22^{\circ}$ colocado em índices de educação) são destaques como estados com baixos indicadores sociais, mas bons rendimentos quando considerada a baixa aplicação de recursos para a área.

O estado do Piaú, também da região Nordeste, apresenta destaque positivo, mas a relação aponta para uma baixa aplicação de recursos ( $6^{\circ}$ menor gasto per capita) e altos indicadores sociais ( $6^{\circ}$ colocado), "puxados para cima" pelas altas taxas de frequência escolar entre a população de 15 a 17 anos, e de 18 a 24 anos, ambas bem superiores à média nacional.

Observa-se que a colocação dos estados no ranking não é o suficiente para oferecer conclusões a respeito de cada elemento. Isto porque uma boa colocação pode vir de uma baixa aplicação de recursos com resultados sociais apenas medianos (Pernambuco, Maranhão, Bahia), ou colocação mediana, apesar de maiores resultados sociais oriundos de altos gastos públicos (Distrito Federal, São Paulo). Nesse sentido, a Figura 2 apresenta uma forma de visualizar os estados na relação indicadores sociais versus aplicação de recursos:

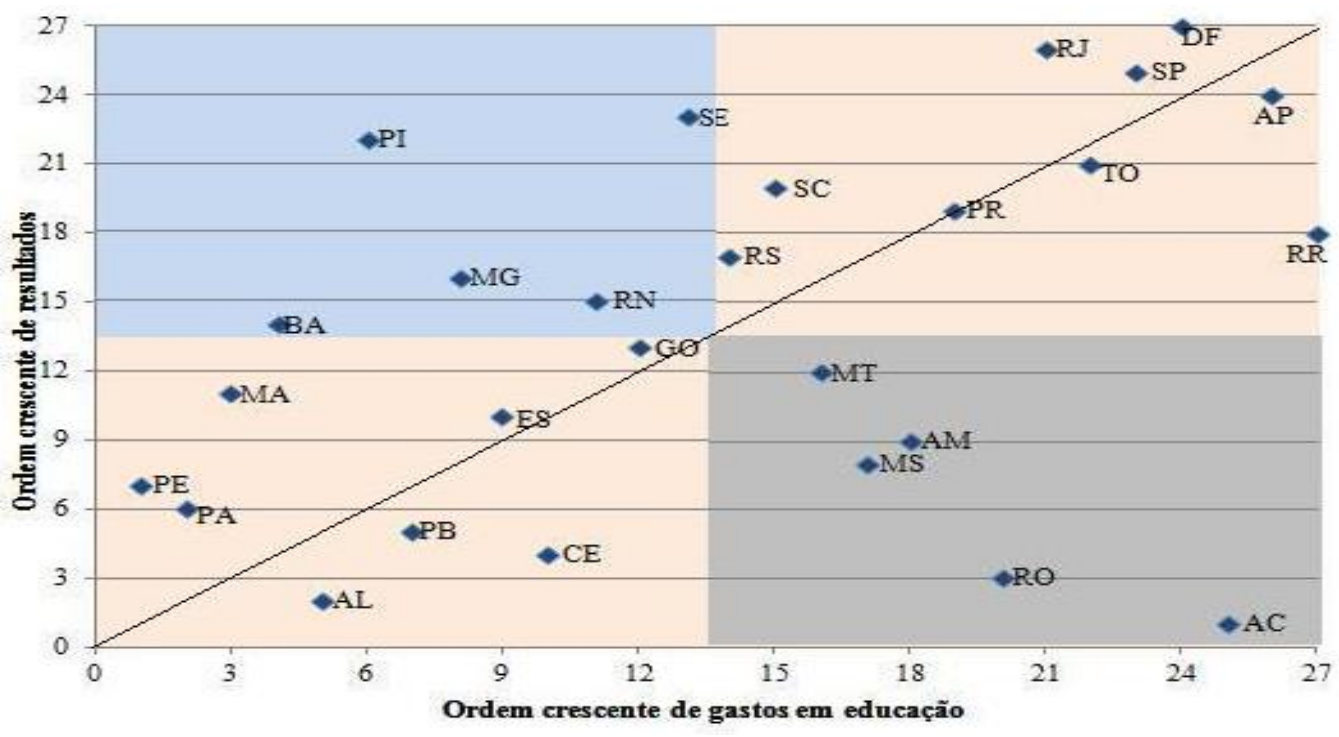

Figura 2: Posicionamento dos estados brasileiros no IQGP.

Fonte: Dados da pesquisa. 
Na Figura 2 podem ser observados os estados com baixos gastos e baixos resultados sociais no quadrante esquerdo inferior, baixos gastos e altos índices sociais no quadrante esquerdo superior, altos gastos e baixos índices sociais no quadrante direito inferior, e altos gastos acompanhados de altos indicadores sociais no quadrante superior direito. Esta forma de visualização complementa o ranking da Tabela 3, que é influenciado pela metodologia de cálculo adotada. De uma forma geral, todos os estados entre a linha diagonal e o eixo das ordenadas (eixo y) estão em uma posição superior nos resultados sociais em educação quando comparados com a sua posição nos gastos per capita. No mesmo raciocínio, os estados que estão entre a linha diagonal e o eixo das abscissas (eixo $x$ ) encontram-se em uma posição inferior nos resultados sociais quando comparados com a sua posição nos gastos per capita.

\section{Conclusões}

A pesquisa aborda a relação entre gastos executados em educação por meio do orçamento público e resultados alcançados pelos estados da Federação considerando os indicadores sociais apontados pelo IBGE. A metodologia adotada oferece um comparativo alcançado ao relacionar as posições dos estados de acordo com o ordenamento de duas variáveis: resultados sociais em educação versus gastos per capita.

Considera-se a existência de limitações ao admitir que os resultados não são alcançados exclusivamente pelos gastos efetuados pelo Poder Público. E, ainda que fossem, não é possível fixar um ponto exato em que os gastos convertam resultados; ou seja, os resultados sociais do ano de 2010 não podem ser comprovadamente frutos de investimentos realizados entre 2001 e 2010 , que são os pontos de corte desta pesquisa.

Este trabalho demonstra, por meio de metodologia quantitativa, uma relação entre investimentos que dão retorno no longo prazo (como os realizados em educação) com o alcance de resultados efetivos para a sociedade, na tentativa de identificar pontos positivos e negativos (estes últimos como consequência dos primeiros) na realização de gastos públicos na área da educação.

A pesquisa alcançou seu objetivo de verificar a relação entre os gastos em educação que os estados realizaram por meio de seu orçamento público e os índices de desempenho relacionados a esta área de despesa. Na seção 4.2 são expostas as considerações sobre a situação verificada, e a Tabela 3 e a Figura 2 oferecem uma síntese visual do cenário encontrado. Para permitir uma comparabilidade dos efeitos que os investimentos em Educação tiveram no resultado do Censo de 2010, foram também coletados e analisados os dados dos gastos em educação, para cada um dos 27 estados brasileiros, entre os anos de 2001 e 2010.

Os estados brasileiros apresentam realidades distintas, com grandes diferenças entre os gastos per capita em educação e também com resultados dos mais diversos, conforme a composição do ranking exposto na Tabela 3. Por meio da Figura 2 verifica-se que alguns estados realizaram altos gastos com educação e obtiveram também altos resultados sociais, como é o caso do Distrito Federal, Rio de Janeiro, São Paulo e Amapá. Neste mesmo sentido, alguns estados realizaram baixos gastos com educação, e obtiveram, consequentemente, baixos resultados sociais, como os estados de Alagoas, Paraíba, Pará e Pernambuco, não obstante estes últimos figurarem entre as melhores colocações do ranking, pois apresentaram posições razoavelmente elevadas quando considerado o baixo investimento realizado em educação.

A situação menos desejada é a obtenção de baixos resultados sociais por meio de altos gastos, situação esta que é verificada nos estados do Acre e de Rondônia, principalmente. Conforme a Figura 1, o estado do Piauí apresentou uma posição desejável, com baixo gasto per capita ( $\$$ 200,42 por ano) e ocupando a sexta colocação em resultados sociais, alavancados principalmente pelas altas taxas de frequência escolar nas várias faixas etárias. Trata-se do estado com destaque, pelo fato de apresentar bons resultados sociais com baixos investimentos: a terceira colocação em qualidade do gasto público é superada por dois estados com baixos resultados sociais justificados por gastos muito abaixo da média nacional.

Conclui-se que a análise da Figura 2 é complementar para a formulação de opiniões e os diferentes contextos também devem ser observados para o alcance de conclusões mais profundas, considerando também a posição no ranking obtida a partir deste estudo.

Como limitações desta pesquisa, consta o fato de o Censo do IBGE ser realizado a cada dez anos, e o último Censo do IBGE ter sido realizado no ano de 2010. Deste modo, não foi possível trabalhar com os dados a partir do ano de 2010. Ou seja, os dados coletados para esta pesquisa referentes aos resultados sociais para cada um dos estados brasileiros referem-se aos resultados do Censo do IBGE do ano de 2010.

E para permitir uma comparabilidade dos efeitos que os investimentos em Educação tiveram no resultado do Censo de 2010, foi necessário coletar dados dos anos anteriores dos gastos em educação, para cada um dos 27 estados brasileiros, entre os anos de 2001 e 2010. Mesmo assim, a série temporal é longa e os dados são de todo o Brasil. Sugere-se, para futuras pesquisas, atualizar estes dados, assim que surgir o novo Censo do IBGE. Considera-se 
que a importância da educação no cenário socioeconômico e a necessidade de racionalização das despesas públicas são motivadores da construção de discussões profundas e podem impulsionar a busca de outros métodos para ratificar ou complementar os resultados por hora encontrados.

\section{Referências}

ALMEIDA, I. C. Gastos com educação no período de 1994 a 1999. Revista Brasileira de Estudos Pedagógicos - RBEP, Brasília, v. 82, n. 200/201/202, p. 137-198, jan./dez. 2001.

ALONSO, M. Custos no serviço público. Revista do Serviço Público/Fundação Escola Nacional de Administração Pública. v. 1, n. 1, ano 50, p. 37-63, jan./mar. 1999.

ANDRADE, D. V. P.; VASCONCElOS, N. V. C.; HÉKIS, H. R.; QUEIROZ, F. C. B. P.; QUEIROZ, J. V. Disclosure e accountability na gestão pública: uma investigação sobre a evidenciação de recursos para educação no Estado do Rio Grande do Norte. Revista Catarinense da Ciência Contábil - CRCSC, Florianópolis, v. 10, n. 28, p. 27-39, dez./mar. 2011.

BILS, M.; KLENOW, P. J. Does schooling cause growth? American Economic Review, 2000, v. 90, n. 5, p. 11601183 .

BORGES, M. F. Qualidade do gasto público municipal: uma abordagem microrregional para o estado do Rio Grande do Sul. 2010. Dissertação (Mestrado em Economia, ênfase em Economia Aplicada). Curso de PósGraduação em Economia. Universidade Federal do Rio Grande do Sul, Porto Alegre, 2010.

BRASIL. Constituição Federal de 1988. Texto Constitucional de 5 de outubro de 1988. Brasília: Senado Federal, 1988.

Portaria MOG n. ${ }^{\circ}$ 42, de 14 de abril de 1999. Atualiza a discriminação da despesa por funções de que

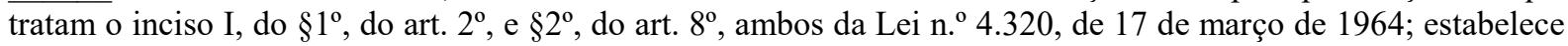
conceitos de função, subfunção, programa, projeto, atividade, operações especiais e dá outras providências. Secretaria de Orçamento Federal. Ministério do Planejamento, Orçamento e Gestão.

BRUNeT, J. F. G.; BERTÊ, A. M. A.; BORGES, C. B. Qualidade do Gasto Público em Educação nas Redes Públicas Estaduais e Municipais. Brasília/DF: Ministério da Fazenda - Secretaria do Tesouro Nacional, 2008 (XIII Prêmio Tesouro Nacional 2008 - Menção Honrosa Finanças Públicas (Tema IV)). Disponível em: http://www.tesouro.fazenda.gov.br/premio_TN/XIIIpremio/qualidade/

MHqualidadeXIIIPTN/Qualidade_Gasto_Publico_Educacao.pdf. Acesso em: 20 mai. 2012.

CASTRO, J. A. Gastos públicos com a educação básica. Revista Brasileira de Estudos Pedagógicos - RBEP, Brasília, v. 79, n. 193, p. 135-147, set./dez. 1998.

COBACHO, B.; CABALLERO, R.; GONZÁLEZ, M.; MOLINA, J. Planning federal public investment in Mexico using multiobjective decision making. Journal of the Operational Research Society, v. 61, n. 9, p. 1328-1339, 2010.

CUNHA, M.; ROCHA, V. On the efficiency of public higher education institutions in Portugal: an exploratory study. FEP Working Paper. University of Porto: 468, 2012.

FARIA, F. P.; JANNUZZI, P. M.; SILVA, S. J. Eficiência dos gastos municipais em saúde e educação: uma investigação através da análise envoltória no estado do Rio de Janeiro. Revista de Administração Pública - RAP, Rio de Janeiro, v. 42, n. 1, p. 155-177, jan./fev. 2008.

GIL, A. C. Como elaborar projetos de pesquisa. $5^{\text {a }}$. ed. São Paulo (SP): Atlas, 2010. 184 p.

IBGE. Censo Populacional 2010. IBGE - Instituto Brasileiro de Geografia e Estatística, 2010. Disponível em: < www.ibge.gov.br>. Acesso em 20 mai. 2012.

JOHNES, J. Data envelopment analysis and its application to the measurement of efficiency in higher education. Economics of Education Review, v. 25, n. 3, p. 273-288, 2006.

KEINERT, T. M. M. Os paradigmas da administração pública no Brasil (1900-92). Revista de Administração de Empresas, v. 34, n. 3, p. 41-48, 1994.

MALCZEWSKI, J.; JACKSON, M. Multicriteria spatial allocation of educational resources: an overview. SocioEconomic Planning Sciences, v. 34, n. 3, p. 219-235, 2000. 
RAUPP, F. M.; BEUREN, I. M. Metodologia da pesquisa aplicável às ciências sociais. In: BEUREN, Ilse Maria. (Org.). Como elaborar trabalhos monográficos em contabilidade: teoria e prática. 2. ed. São Paulo: Atlas, 2004. p. 76-97.

RENZI, A. Gasto público em educação e produtividade do trabalho num modelo Kaleckiano. 2008. Dissertação (Mestrado em Desenvolvimento Econômico). Curso de Pós-Graduação em Desenvolvimento Econômico. Universidade Federal do Paraná, Curitiba, 2008.

REZENDE, F.; CUNHA, A.; BEVILACQUA, R. Informações de custos e qualidade do gasto público: lições da experiência internacional. Revista de Administração Pública - RAP, Rio de Janeiro, v. 44, n. 4, p. 959-992, jul./ago. 2010.

ROCHA, F.; GIUBERTI, A. C. Composição do gasto público e crescimento econômico: uma avaliação macroeconômica da qualidade dos gastos dos Estados brasileiros. Economia Aplicada, v. 11, n. 4, p. 463-485, out./dez. 2007.

ROSA, M. B.; TIMBÓ, M. Z. F.; PISCITELLI, R. B. Contabilidade Pública: Uma abordagem da Administração Financeira Pública. 5a . ed., São Paulo, 1997, 330 p.

SALOMON, D. V. Como fazer uma monografia. 4a . ed. São Paulo: Martins Fontes, 1996. 294 p.

SANO, K.; TOMODA, Y. Optimal public education policy in a two sector model. Economic Modelling, v. 27, p. 991-995, 2010.

SILVA, L. M. Contabilidade Governamental: Um enfoque Administrativo. 7ª ed., São Paulo: Atlas, 2004. 385 p.

SILVA, M. C.; AQUINO, Í. P. B.; OLIVEIRA, E. J.; BATISTA, E. M. Gastos com educação: análise da aplicação de recursos pelos municípios do estado do Rio Grande do Norte, no período de 2006 a 2009. Enfoque: Reflexão Contábil, Maringá, v. 30, n. 2, p. 67-82, mai./ago. 2011.

SLOMSKI, V.; CAMARGO, G. B.; AMARAL FILHO, A. C. C.; SLOMSKI, V. G. A demonstração do resultado econômico e sistemas de custeamento como instrumentos de evidenciação do cumprimento do princípio constitucional da eficiência, produção de governança e accountability no setor público: uma aplicação na Procuradoria Geral do Município de São Paulo. Revista de Administração Pública - RAP, Rio de Janeiro, v. 44, n. 4, p. 933-957, jul./ago. 2010.

SOBREIRA, R.; CAMPOS, B. C. Investimento público em educação fundamental e a qualidade do ensino: uma avaliação regional dos resultados do Fundef. Revista de Administração Pública - RAP, Rio de Janeiro, v. 42, n. 2, p. 327-346, mar./abr. 2008.

STN - Secretaria do Tesouro Nacional; SOF - Secretaria de Orçamento Federal. Execução orçamentária dos estados: 1995-2011. Disponível em: <www.stn.fazenda.gov.br>. Acesso em: 20 mai. 2012. 